Editorial

\title{
Sustainable Supply Chain System Design and Optimization
}

\author{
Sadok Turki * and Nidhal Rezg \\ Laboratory of Informatics Engineering and Production of Metz, UFR MIM, 3 Rue Augustin Fresnel, \\ F-57070 Metz, France; nidhal.rezg@univ-lorraine.fr \\ * Correspondence: sadok.turki@univ-lorraine.fr
}

Received: 19 February 2019; Accepted: 21 February 2019; Published: 23 February 2019

\begin{abstract}
Due to increasing concerns about the environment, potential economic benefits and legislation pressure; supply chain management has changed to focus on the environmental impacts of production and Earth resource preservation. Therefore, many managers are working hard on improving the sustainability of their supply chain systems. In this paper, we present the themes addressed, and the approaches used in this special issue to investigate the design and optimization of sustainable supply chain systems. Firstly, we introduce the topics under investigation, and then we present the published articles to discuss the benefits of sustainable supply chain systems in raising profits and improving ecology. This issue increases our knowledge of the sustainable supply chain systems design and sustainable strategies.
\end{abstract}

Keywords: manufacturing and remanufacturing supply chains; discrete flow model; returned-used products quality; optimization methods; carbon emissions

\section{Contents of the Special Issue}

Due to legislation constraints, potential economic benefits and environmental regulations, production firms are obliged to commit to the development of sustainable supply chains. Today, the attention of many academic researchers and company leaders is on the management and design of sustainable supply chains turn. As a result, company leaders are working hard to propose and establish new sustainable strategies, optimize designs and create innovative production practices, in order to curb carbon emissions and maximize profits. In the literature, a large number of research papers deal with sustainable supply chains. Indeed, most sustainable supply chains are formed by including information about remanufacturing activities with the manufacturing of a new product. The activity of remanufacturing products is vital to sustainable development, as it allows the product life cycle to be extended, and decreases the depletion of resources, therefore offering ecologic and economic benefits. That said, few published works in the literature deal with the design and the optimal decisions within sustainable supply chains. Therefore, to bridge this gap in the literature, the proposed thematic issue aims to contribute to the existing literature by investigating new sustainable strategies and optimal designs of sustainable supply chain systems. This special issue adds new knowledge to the existing body of literature on design and optimization of sustainable supply chain systems. The first group of papers focuses on the supply chain coordination. The second group develops the topic of recycling strategies and decisions. Eighteen articles are included in the special issue.

\section{List of Contributions}

1. Huang, Y.; Wang, Z. Dual-Recycling Channel Decision in a Closed-Loop Supply Chain with Cost Disruptions. 
2. Huang, M.; Yi, P.; Shi, T. Triple Recycling Channel Strategies for Remanufacturing of Construction Machinery in a Retailer-Dominated Closed-Loop Supply Chain.

3. He, X.; Zhang, J. Supplier Selection Study under the Respective of Low-Carbon Supply Chain: A Hybrid Evaluation Model Based on FA-DEA-AHP.

4. Yuan, B.; Gu, B.; Guo, J.; Xia, L.; Xu, C. The Optimal Decisions for a Sustainable Supply Chain with Carbon Information Asymmetry under Cap-and-Trade.

5. Son, D.; Kim, S.; Park, H.; Jeong, B. Closed-Loop Supply Chain Planning Model of Rare Metals.

6. Liu, Y.; Zhang, Y. Closed Loop Supply Chain under Power Configurations and Dual Competitions.

7. Han, Q.; Wang, Y. Decision and Coordination in a Low-Carbon E-Supply Chain Considering the Manufacturer's Carbon Emission Reduction Behavior.

8. Nadal-Roig, E.; Pagès-Bernaus, A.; Plà-Aragonès, L. Bi-Objective Optimization Model Based on Profit and CO2 Emissions for Pig Deliveries to the Abattoir.

9. Guo, H.; Li, C.; Zhang, Y.; Zhang, C.; Lu, M. A Location-Inventory Problem in a Closed-Loop Supply Chain with Secondary Market Consideration.

10. Xu, F.; Wang, H. Competitive-Cooperative Strategy Based on Altruistic Behavior for DualChannel Supply Chains.

11. Choi, S. A Loss-Averse Newsvendor with Cap-and-Trade Carbon Emissions Regulation.

12. Liu, A.; Xiao, Y.; Ji, X.; Wang, K.; Tsai, S.; Lu, H.; Cheng, J.; Lai, X.; Wang, J. A Novel Two-Stage Integrated Model for Supplier Selection of Green Fresh Product.

13. Wang, J.; Wu, Y. An Improved Voronoi-Diagram-Based Algorithm for Continuous Facility Location Problem under Disruptions.

14. Turki, S.; Rezg, N. Impact of the Quality of Returned-Used Products on the Optimal Design of a Manufacturing/Remanufacturing System under Carbon Emissions Constraints.

15. Zou, H.; Qin, J.; Yang, P.; Dai, B. A Coordinated Revenue-Sharing Model for a Sustainable Closed-Loop Supply Chain.

16. Xue, K.; Xu, Y.; Feng, L. Managing Procurement for a Firm with Two Ordering Opportunities under Supply Disruption Risk.

17. Troudi, A.; Addouche, S.; Dellagi, S.; Mhamedi, A. Sizing of the Drone Delivery Fleet Considering Energy Autonomy.

18. Arshad, M.; Khalid, Q.; Lloret, J.; Leon, A. An Efficient Approach for Coordination of Dual-Channel Closed-Loop Supply Chain Management.

Conflicts of Interest: The authors declare no conflict of interest. 